\title{
Molecular Docking Studies of Natural Immunomodulators Indicate Their Interactions With CD40 and CSF1 of Microglia
}

\section{Shashank Kumar Maurya}

University of Delhi

Rajnikant Mishra ( $\nabla$ rmishraa@bhu.ac.in )

Banaras Hindu University https://orcid.org/0000-0002-6714-1460

\section{Research Article}

Keywords: Microglia, Natural Products, Protein-Ligand Interaction, Drug Target, Molecular Docking, MD Simulation

Posted Date: January 12th, 2022

DOI: https://doi.org/10.21203/rs.3.rs-1158486/v1

License: (c) (i) This work is licensed under a Creative Commons Attribution 4.0 International License. Read Full License 


\section{Abstract}

Natural products have proved beneficial in reducing neuroinflammation in neurological diseases. Their impacts have also been associated with the activities of microglia, responsible for brain-specific immunity. Recent studies have shown involvement of the number of microglia-specific proteins in the regulation of brain-specific immunity. However, molecular targets of natural products and their mechanisms of interactions with microglia-specific proteins are elusive. Since the genetic signature of microglia offers many potential targets for drug discovery, molecular docking followed by Molecular Dynamics (MD) simulations of Cluster of Differentiation 40 (CD40) and Colony-stimulating factor 1 receptor (CSF1R) proteins with some known neuro-immunomodulators (Curcumin, Cannabidiol, Ginsenosides, Resveratrol, and Sulforaphane) has been evaluated. Curcumin and Cannabidiol were observed likely to modulate CD40L and expression of cytokines and entry of inflammatory cells. Resveratrol and Cannabidiol may affect CSF1R and activation of microglia. Our finding suggests that Curcumin, Cannabidiol, and Resveratrol may serve specific drug ligands in regulating microglia-mediated brain immunity.

\section{Introduction}

Natural products are defined as small molecules produced by living organisms. The major advantages of using these natural products are their novel structure, multi-target molecular mechanism, potent efficiency, and safe pharmacodynamics. Recent researches have shown the use of natural products like Curcumin, Cannabidiol, Ginsenosides, Resveratrol, and Sulforaphane on brain immunity and neurodegenerative diseases [1-4]. However, natural products mediated molecular targets of microglia are still elusive.

Microglia, resident immune cells of the immune-privileged brain, regulate brain homeostasis in response to pathogen and injury by accumulating at the site of inflammation or degeneration. They facilitate induction of a wide variety of cytokines, regulate neurogenesis, synaptic pruning, laminar structure of cortex, and neurite formation [5-12]. The local microenvironment of neurons and astrocytes also affects phenotypes of microglia by interaction with both soluble and membrane-bound mediators [13]. Depending on the strength of injury, microglia may have neuroprotective or neuroinflammatory functions. In case of short signal, microglia secretes growth factors to heal damaged neurons, cause phagocytosis of cell debris indicating neuroprotective phenotype whereas cause neuronal damage by secreting proinflammatory cytokines, reactive oxygen species, and nitric oxide in response to an acute and chronic signal which further recruits lymphocytes from blood to damage site [9]. Upregulated expression of CD40 on the surface of activated microglia and its ligation with soluble ligands leads to increased secretion of numerous pro-inflammatory mediators by microglia [14]. The CSF1R, a key signaling node, regulates the development, proliferation, migration, differentiation, and survival of microglia [15]. Anti-inflammatory neuropeptide, pituitary adenylyl cyclase-activating polypeptide (PACAP), lovastatin, and glucocorticoids down-regulate the expression of CD40 in activated microglia [16-18]. The CSF1R inhibitors (PLX3397 and PLX5622) cause depletion of microglia and prevent plaque formation in brain parenchyma in the 5xFAD 
mouse model of AD [19-20]. Another CSF1R inhibitor JNJ-40346527 (JNJ-527) blocks the proliferation of microglial and attenuation of tau-induced neurodegeneration [21].

Therefore, it is aimed to identify the possible microglia-specific molecular target of natural products (Curcumin, Cannabidiol, Ginsenosides, Resveratrol, and Sulforaphane) using in silico docking studies.

\section{Materials And Methods}

\section{Retrieval of the 3D structure of natural products}

The structures of natural products Curcumin (PubChem CID: 969516), Cannabidiol (PubChem CID: 644019), Ginsenosides (Rg1) (PubChem CID: 441923), Resveratrol (PubChem CID: 445154) and Sulforaphane (PubChem ID: 5350) regained from PubChem (https://pubchem.ncbi.nlm.nih.gov/). The SDF (Structure Data Format) file of the five natural products was downloaded from PubChem Database using default parameters and converted to a PDB file using Open Babel software [22].

\section{Drug likeness of the natural products}

The drug likeliness properties of the five natural products (Curcumin, Cannabidiol, Resveratrol, Ginsenosides Rg1, and Sulfopharane) were evaluated with the help of Lipinski drug filter rule of 5 (molecular mass, number of hydrogen bond donors, and acceptors, logP and molar refractivity) from supercomputing facility for bioinformatics and computational biology (http://www.scfbioiitd.res.in/software/drugdesign/lipinski.jsp) [23]. Based on the Lipinski rule of five which includes parameters such as (i) molecular mass should be less than 500 Dalton, (ii) hydrogen bond donor should be less than 5 , (iii) hydrogen bond acceptor should be less than 10 , (iv) molar refractivity must lie between 40 and 130 (v) high lipophilicity (expressed as LogP) should be less than 5 , the drug-like or nondrug like properties of the molecule can be calculated.

\section{ADME toxicity of natural products}

Absorption, distribution, metabolism, excretion, and toxicity (ADMET) studies of the five natural products (Curcumin, Cannabidiol, Resveratrol, Ginsenosides Rg1. and Sulfopharane) were performed to identify potential pharmacologically active compounds [23-24] using Web-based admetSAR tool (https://Immd.ecust.edu.cn:8000). ADME toxicity parameters include: (i) Human intestinal absorption (\%) studies to determine the bioavailability (oral ingestion) of the compound, (ii) Blood-brain penetration studies to know the Central Nervous System (CNS) side effects caused by the compound, (iii) mutagenicity and (iv) carcinogenicity testing.

\section{Retrieval of the 3D structure of proteins and analysis for drug pocket predictions}

The PDB file of 3D structure of CD40 (PDB ID: 1ALY) and CSF1R (PDB ID: 6T2W) was retrieved from Protein Data Bank (https://www.rcsb.org/). The DoGSiteScorer server was used to visualize potential 
drug binding pockets on protein structure where drug score determines the druggability of the pocket [25].

\section{Molecular Docking and analysis of protein-ligand interaction}

The molecular docking was performed by AutoDock 4.2 [26] using AutoDock Tools- 1.5.6. Briefly, the PDB file of protein was opened in AutoDock Tools. The water molecules and any bound ligand were deleted followed by the addition of Kollman Charges on the protein molecule. The PDB file of natural products was converted to a PDBQT file using Open Babel software and then created PDBQT file was opened into the AutoDock Tools. The grid parameters were selected to cover the whole protein structure for the analysis. Then, docking was performed using genetic algorithm (GA) as a search parameter for 50 runs and a population size of 300 . After docking, the docking complex was retrieved from AutoDock Tools in PDBQT file format which was further converted to PDB file format using Open Babel. Interaction between ligand and targets was calculated on the basis of binding energy ( $\mathrm{Kcal} / \mathrm{mol})$, inhibition constant $(\mu \mathrm{M})$, and contacting receptor residues. The protein-ligand interaction and analysis of hydrogen bond formation were analyzed by LigPlot2 [27] and Protein-Ligand Interface Profiler (PLIP) server [28]. The docking results were further validated by protein with ligand simulation for 100ns using GROMAC simulation package by online WEBGRO server [29] of Simlab (https://simlab.uams.edu/). The best binding pose of protein-ligand complex obtained through docking was taken as input for Molecular Dynamics (MD) simulations. System and structural stability were monitored by measuring the RMSD, RMSF, and Rg of the protein-ligand complex (Supplementary Figure 1-6). The stability of ligand inside the binding pocket of protein was assessed by measuring the RMSD of ligand. The effect of ligand on protein mobility or movement was measured through RMSF. Effect of ligand-protein compactness was measured through $\mathrm{Rg}$ with respect to time.

\section{Results}

\section{Curcumin, Cannabidiol, and Resveratrol obeys Lipinski rule of 5 indicating their drug-like property}

Out of five compounds, only Curcumin, Cannabidiol and Resveratrol obeyed the Lipinski rule of 5 (viz. molecular mass should be less than 500 Dalton, high lipophilicity expressed as LogP less than 5 , hydrogen bond donor should be less than 5 , less than 10 hydrogen bond acceptor, molar refractivity must lie between 40 and 130). The molecular mass of Curcumin, Cannabidiol, and Resveratrol are 314, 368, and 228 Dalton, respectively. LogP values of Curcumin, Cannabidiol, and Resveratrol are 5.846501, 3.410700 , and 3.304500, respectively. Hydrogen bond donors of Curcumin, Cannabidiol, and Resveratrol are 2, 2, and 3, respectively. While hydrogen bond acceptors of Curcumin, Cannabidiol, and Resveratrol are 2, 6, and 3. Molar refractivity of Curcumin, Cannabidiol, and Resveratrol are 97.036560, 101.350578, and 66.581390 (Table 1).

ADME toxicity screening indicates Curcumin, Cannabidiol, Resveratrol, and Ginsenoside RG1 as potential pharmacologically active compound 
ADMET studies of all the five natural products were executed to screen the most efficacious pharmacologically active compound. Based on the ADME toxicity investigation result, it was found that all the five natural products have the ability to absorb in the blood-brain barrier. Out of five, Curcumin, Cannabidiol, Resveratrol, and Ginsenoside RG1 showed oral bioavailability, non-toxic and noncarcinogenic properties (Table 2).

\section{Molecular docking showed potential interaction of Curcumin and Cannabidiol with CD40}

The analysis of CD40 protein showed presence of 5 drug pockets (Table 3 ) which can be used for drug binding. The protein-ligand interaction using Curcumin and Cannabidiol as ligand showed its binding to drug pocket 0 of CD40 with a volume of $269.18 \AA^{3}$ and surface area of $471.12 \AA^{2}$ and drug score of 0.62 whereas Resveratrol does not show binding on predicted drug binding sites (Figure 2). The visualization of CD40 interaction with Curcumin showed 2 hydrogen bonds between Asp243 and Ser245 residue of CD40 with Curcumin has a distance of 2.85 and $2.87 \AA$, respectively and binding energy of $-4.69 \mathrm{Kcal} / \mathrm{Mol}$ and inhibition constant of value $367.48 \mu \mathrm{M}$. Similarly with Cannabidiol, the binding energy obtained was $-4.22 \mathrm{Kcal} / \mathrm{Mol}$ and an inhibition constant value of $805.16 \mu \mathrm{M}$. The Ser245 amino acids of CD 40 form 2 hydrogen bond with Cannabidiol with distances between them are 3.08 and $3.10 \AA$, respectively. The resveratrol shows hydrogen binding with 4 amino acids (Val175, Ala173, Ile171, Gly227) of CD40 where lle171 forms 2 hydrogen bonds of 3.24 and $2.46 \AA$ whereas Val175, Ala173, and Gly227 form one hydrogen bond with resveratrol of 3.01, 2.74, and $2.66 \AA$ each (Figure 3; Table 4).

\section{Resveratrol and Cannabidiol seems promising for targeting CSF1R protein kinase domain}

The analysis of CSF1R protein showed presence of 13 drug pockets that can be used for drug binding (Table 5). The protein-ligand interaction using Cannabidiol and Resveratrol as ligand showed its binding to drug pocket 0 of CSF1R with a volume of $1254.85 \AA^{3}$, surface area of $1374.39 \AA^{2}$, and drug score of 0.82. However, binding of Curcumin was observed away from the predicted drug pocket of CSF1R (Figure 4). Further, docking of CSF1R with Curcumin showed binding energy of $-4.95 \mathrm{Kcal} / \mathrm{Mol}$ and an inhibition constant of value $236.48 \mu \mathrm{M}$. The 4 hydrogen bond between Arg579, Gly603, Gly605, and His655 residues of CSF1R with Curcumin has a distance of $3.07,3.13,2.56$, and $2.96 \AA$, respectively. Similarly with Cannabidiol, the binding energy obtained is $-4.75 \mathrm{Kcal} / \mathrm{Mol}$, and the inhibition constant value of $328.22 \mu \mathrm{M}$. The Asp670 amino acid of CSF1R forms 2 hydrogen bonds with Cannabidiol with a distance between them are 3.23 and $2.69 \AA$, respectively and Leu588 amino acid forms a single hydrogen bond with a distance of $2.83 \AA$ with Cannabidiol. The Resveratrol shows hydrogen binding with 4 amino acids (Lys616, Cys666, Gly669, and Phe797) of CSF1R with a distance of 3.18, 2.85, 3.53, $3.99 \AA$, respectively, binding energy obtained is $-5.91 \mathrm{Kcal} / \mathrm{Mol}$ and inhibition constant value of $46.94 \mu \mathrm{M}$ (Figure 5; Table 6).

\section{MD simulation of CD40 and CSF1R-ligand complexes}

It was observed that RMSD of CD40 in CD40-Cannabidiol complex showed equilibrium with average RMSD value of around $0.25 \mathrm{~nm}$ (Supplementary Figure 1A). The major oscillations in RMSD of Cannabidiol in CD 40-Cannabidiol complex were observed at 0-50 ns. After $50 \mathrm{~ns}$, RMSD of ligand was 
stabilized with an average value of approx. $1.75 \mathrm{~nm}$ (Figure 1B) though major oscillations recurred during 70-75 ns (Figure 1B). The CD40-Cannabidiol complex showed minor fluctuation between $0.2 \mathrm{~nm}$ to $0.45 \mathrm{~nm}$ during the entire simulation period (Figure $1 \mathrm{C}$ ). It was observed that $\mathrm{Rg}$ of CD40 in the CD40Cannabidiol complex did not show major fluctuation with an average value of $1.53 \mathrm{~nm}$ (Figure 1D).

A similar observation was also noted for CD40-Curcumin (Supplementary Figure 2A-D), CD40-Resveratrol (Supplementary Figure 3A-D), CSF1R-Cannabidiol (Supplementary Figure 4A-D), CSF1R-Curcumin (Supplementary Figure 5A-D), and CSF1R-Resveratrol complex (Supplementary Figure 6A-D).

\section{Discussion}

Among analyzed natural products, Curcumin, Cannabidiol, and Resveratrol fulfilled all 5 criteria of the Lipinski rule [30] which may prove as potential drug-like compounds. Observations also indicate that natural products Curcumin, Cannabidiol, and Resveratrol can be used as a drug target for microgliamediated neuroinflammation. They also obey ADMET (Absorption, distribution, metabolism, excretion, and toxicity) properties useful for early preclinical drug screening and development [24].

It was observed that the lower the binding energy between protein-ligand interactions, higher the affinity of a ligand for the protein where the presence of hydrogen bond and other hydrophobic interactions helps in forming good binding affinity [31]. Further, the presence of amino acid residues Gly, Ser, His, Trp, Tyr, Arg, and Asp were more abundant at the ligand-binding site of a protein and were found involved in the formation of hydrogen bond, hydrophobic bond, and salt bridge interaction between protein and ligand [32]. According to the DoGSiteScorer server for identification of drug pockets on protein, pocket with drug score of near to 1 and volume more than $500 \AA$ are considered more likely to be perfect druggable site $[25,33]$. Results are in agreement with other reports on inhibition of the protein ${ }^{34-35}$.

Curcumin and Cannabidiol have similar binding energy but the inhibition constant is lowest for Curcumin with CD40. Resveratrol forms the maximum hydrogen bond with CD40 amino acids and showed a positive high value of binding energy which indicates unfavorable interaction among them. The CD40, a 45 to $50 \mathrm{kDa}$ type I membrane glycoprotein, gets upregulated under pro-inflammatory and HIV-infected brain [36-37]. The Protein-ligand interaction study indicates that Curcumin and Cannabidiol could possibly bind to a druggable pocket of CD40 and may interfere with CD40-CD40L interactions, accelerating the expression of chemokines and entry of inflammatory cells in the CNS.

The interaction of natural products with colony-stimulating factor 1 receptor (CSF1R) would be useful to modulate survival, maintenance, proliferation, and activation of microglia or activated microglia-mediated functions in normal and disease conditions [38-41]. The evaluation of results indicates that Resveratrol and Cannabidiol could be efficient in inhibiting the CSF1R mediated signaling which can further prevent microglial activation and even microglia-mediated demyelination in neurological diseases. Resveratrol showed the lowest inhibition constant value among all. Curcumin and Resveratrol form the maximum hydrogen bond with CSF1R amino acids followed by Cannabidiol but Curcumin does not show binding at 
the predicted druggable site. Resveratrol and Cannabidiol bind to the most likely druggable pocket as compared to other natural products.

Overall, values of RMSD, RMSF, Rg of protein-ligand complexes observed in permissible limit. MD simulation of CD40 and CSF1R-ligand complexes suggested that while the complex showed stable and consistent behavior of RMSD and Rg, fluctuation at a particular region of protein helped to acquire the stable conformation during ligand binding. Our study indicates the possible involvement of Curcumin, Cannabidiol, and Resveratrol towards functions of CD40 and CSR1F on microglia (Figure 5).

\section{Conclusion}

Our finding suggests potential interaction between natural products and microglia-specific proteins. Druggable pockets, binding energy, inhibition constant, and formation of stable hydrogen bonds between natural products and microglia proteins suggest that Curcumin, Cannabidiol, and Resveratrol can be used for targeting proteins involved in microglia activation during neuroinflammation and neurodegeneration.

\section{Declarations}

\section{Statements and Declarations}

Funding: The authors declare that no funds, grants, or other support were received during the preparation of this manuscript

Conflict of interest/Competing interests: The authors have no relevant financial or non-financial interests to disclose.

Availability of data and material: The datasets generated during and/or analyzed during the current study are available from the corresponding author on reasonable request.

Code availability: Not applicable

Author's contributions: SKM and RM conceptualized the manuscript. SKM perform the experiments and wrote the initial draft of the manuscript. RM supervised the study, reviewed and edited the manuscript. All the authors approved the manuscript before submission.

Acknowledgment: SKM acknowledges Ramjas College, University of Delhi, Delhi for its continuous support and motivation.

\section{References}

1. Choi DK, Koppula S, Suk K (2011) Inhibitors of microglial neurotoxicity: focus on natural products. Molecules 16:1021-1043. 
2. Silva AR, Grosso C, Delerue-Matos C, Rocha JM (2019) Comprehensive review on the interaction between natural compounds and brain receptors: Benefits and toxicity. Eur J Med Chem 174:87-115.

3. Jin X et al. (2019) Natural products as a potential modulator of microglial polarization in neurodegenerative diseases. Pharmacol Res 145:104253.

4. Maurya SK et al. (2021) Microglia Specific Drug Targeting Using Natural Products for the Regulation of Redox Imbalance in Neurodegeneration. Front Pharmacol 12:654489.

5. Kim YS, Joh TH (2006) Microglia, major player in the brain inflammation: their roles in the pathogenesis of Parkinson's disease. Exp Mol Med 38:333-347.

6. Paolicelli RC et al. (2011) Synaptic pruning by microglia is necessary for normal brain development. Science 333:1456-1458.

7. Pont-Lezica L, Béchade C, Belarif-Cantaut Y, Pascual O, Bessis A (2011) Physiological roles of microglia during development. J Neurochem 119:901-908.

8. Li Y, Du XF, Liu CS, Wen ZL, Du JL (2012) Reciprocal regulation between resting microglial dynamics and neuronal activity in vivo. Dev Cell 23:1189-1202.

9. London A, Cohen M, Schwartz M (2013) Microglia and monocyte-derived macrophages: functionally distinct populations that act in concert in CNS plasticity and repair. Front Cell Neurosci 7:34.

10. Cunningham CL, Martínez-Cerdeño V, Noctor SC (2013) Microglia regulate the number of neural precursor cells in the developing cerebral cortex. J Neurosci 33:4216-4233.

11. Nayak D, Roth TL, McGavern DB (2014) Microglia development and function. Annu Rev Immunol 32:367-402.

12. Squarzoni P et al. (2014) Microglia modulate wiring of the embryonic forebrain. Cell Rep 8:12711279.

13. Wohleb ES (2016) Neuron-Microglia Interactions in Mental Health Disorders: "For Better, and For Worse". Front Immunol 7:544.

14. D'Aversa TG, Eugenin EA, Berman JW (2008) CD40-CD40 ligand interactions in human microglia induce CXCL8 (interleukin-8) secretion by a mechanism dependent on activation of ERK1/2 and nuclear translocation of nuclear factor-kappa B (NF kappa B) and activator protein-1 (AP-1). J Neurosci Res 86:630-639.

15. Hagan N et al. (2020) CSF1R signaling is a regulator of pathogenesis in progressive MS. Cell Death Dis 11:904.

16. Kim WK, Ganea D, Jonakait GM (2002) Inhibition of microglial CD40 expression by pituitary adenylate cyclase-activating polypeptide is mediated by interleukin-10. J Neuroimmunol 126:16-24.

17. Townsend KP et al. (2004) Lovastatin modulation of microglial activation via suppression of functional CD40 expression. J Neurosci Res 78:167-176.

18. Li M, Wang Y, Guo R, Bai Y, Yu Z (2007) Glucocorticoids impair microglia ability to induce T cell proliferation and Th1 polarization. Immunol Lett 109:129-137. 
19. Sosna J et al. (2018) Early long-term administration of the CSF1R inhibitor PLX3397 ablates microglia and reduces accumulation of intraneuronal amyloid, neuritic plaque deposition and prefibrillar oligomers in 5XFAD mouse model of Alzheimer's disease. Mol Neurodegener 13:11.

20. Spangenberg E et al. (2019) Sustained microglial depletion with CSF1R inhibitor impairs parenchymal plaque development in an Alzheimer's disease model. Nat Commun 10:3758.

21. Mancuso R et al. (2019) CSF1R inhibitor JNJ-40346527 attenuates microglial proliferation and neurodegeneration in P301S mice. Brain 142:3243-3264.

22. O'Boyle NM, Banck M, James CA, Morley C, Vandermeersch T, Hutchison GR. Open Babel: An open chemical toolbox. J Cheminform 2011;3:33.

23. Jayaram B, Singh T, Mukherjee G, Mathur A, Shekhar S, Shekhar V. Sanjeevini: a freely accessible web-server for target directed lead molecule discovery. BMC Bioinformatics 2012;13 Suppl 17(Suppl 17):S7. doi:10.1186/1471-2105-13-S17-S7

24. Cheng F, Li W, Zhou Y, et al. admetSAR: a comprehensive source and free tool for assessment of chemical ADMET properties. Journal of Chemical Information and Modeling. 2012;52(11):30993105. DOI: 10.1021/ci300367a. PMID: 23092397.

25. Volkamer A, Kuhn D, Grombacher T, Rippmann F, Rarey M (2012) Combining global and local measures for structure-based druggability predictions. J Chem Inf Model 52:360-372.

26. Morris GM et al. (2009) AutoDock4 and AutoDockTools4: Automated docking with selective receptor flexibility. J Comput Chem 30:2785-2791.

27. Laskowski RA, Swindells MB (2011) LigPlot+: multiple ligand-protein interaction diagrams for drug discovery. J Chem Inf Model 51:2778-2786.

28. Adasme MF et al. (2021) PLIP 2021: expanding the scope of the protein-ligand interaction profiler to DNA and RNA. Nucleic Acids Res gkab294.

29. Bjelkmar P, Larsson P, Cuendet MA, Hess B, Lindahl E. Implementation of the CHARMM Force Field in GROMACS: Analysis of Protein Stability Effects from Correction Maps, Virtual Interaction Sites, and Water Models. J Chem Theory Comput. 2010;6(2):459-466. doi:10.1021/ct900549r

30. Lipinski CA, Lombardo F, Dominy BW, Feeney PJ. Experimental and computational approaches to estimate solubility and permeability in drug discovery and development settings. Advanced Drug Delivery Reviews 1997;23(1-3): 3-25. doi:10.1016/s0169-409x(00)00129-0

31. Azam SS, Abbasi SW (2013) Molecular docking studies for the identification of novel melatoninergic inhibitors for acetylserotonin-0-methyltransferase using different docking routines. Theor Biol Med Model 10:63.

32. Villar HO, Kauvar LM (1994) Amino acid preferences at protein binding sites. FEBS Lett 349:125130.

33. Drew ED, Janes RW (2020) Identification of a druggable binding pocket in the spike protein reveals a key site for existing drugs potentially capable of combating Covid-19 infectivity. BMC Mol Cell Biol 21:49. 
34. Pantsar T, Poso A (2018) Binding Affinity via Docking: Fact and Fiction. Molecules 23:1899.

35. Sliwoski G, Kothiwale S, Meiler J, Lowe EW, Jr (2013) Computational methods in drug discovery. Pharmacol Rev 66:334-395.

36. Sui $Z$ et al. (2007) Functional synergy between CD 40 ligand and HIV-1 Tat contributes to inflammation: implications in HIV type 1 dementia. J Immunol 178:3226-3236.

37. Pluvinet $R$ et al. (2008) CD40: an upstream master switch for endothelial cell activation uncovered by RNAi-coupled transcriptional profiling. Blood 112:3624-3637.

38. Michell-Robinson MA et al. (2015) Roles of microglia in brain development, tissue maintenance and repair. Brain 138:1138-1159.

39. Oosterhof $\mathrm{N}$ et al. (2018) Colony-Stimulating Factor 1 Receptor (CSF1R) Regulates Microglia Density and Distribution, but Not Microglia Differentiation In Vivo Cell Rep 24:1203-1217.

40. Martin-Estebane M, Gomez-Nicola D (2020) Targeting Microglial Population Dynamics in Alzheimer's Disease: Are We Ready for a Potential Impact on Immune Function?. Front Cell Neurosci 14:149.

41. Marzan DE, Brügger-Verdon V, West BL, Liddelow S, Samanta J, Salzer JL (2021) Activated microglia drive demyelination via CSF1R signaling. Glia 69:1583-1604.

\section{Tables}

Table 1: Drug likeliness using Lipinski rule of 5 for natural products

\begin{tabular}{llllllll} 
S.No. & $\begin{array}{l}\text { Compound } \\
\text { Name }\end{array}$ & $\begin{array}{l}\text { Mass } \\
\text { (less } \\
\text { than } \\
500)\end{array}$ & $\begin{array}{l}\text { Hydrogen } \\
\text { bind } \\
\text { donor } \\
\text { (less than } \\
5)\end{array}$ & $\begin{array}{l}\text { Hydrogen } \\
\text { bond } \\
\text { acceptors } \\
\text { (less than } \\
10)\end{array}$ & $\begin{array}{l}\text { LOGP } \\
\text { (less } \\
\text { than 5) }\end{array}$ & $\begin{array}{l}\text { Molar } \\
\text { refractivity } \\
\text { (should be } \\
\text { between 40 } \\
\text { and 130) }\end{array}$ & Status \\
\hline 1. & Cannabidiol & 314 & 2 & 2 & 5.846501 & 97.036560 & Accepted \\
\hline 2. & Curcumin & 368 & 2 & 6 & 3.410700 & 101.350578 & Accepted \\
\hline 3. & Resveratrol & 228 & 3 & 3 & 3.304500 & 66.581390 & Accepted \\
\hline 4. & $\begin{array}{l}\text { Ginsenoside } \\
\text { RG1 }\end{array}$ & 728 & 0 & 14 & 0.340680 & 152.853409 & Rejected \\
\hline 5. & Sulforaphane & 177 & 0 & 1 & 1.563550 & 49.301895 & Rejected
\end{tabular}

\section{Table 2: ADMET properties of the natural products}




\begin{tabular}{|c|c|c|c|c|c|c|}
\hline S.No. & $\begin{array}{l}\text { Compound } \\
\text { Name }\end{array}$ & $\begin{array}{l}\text { Blood-brain } \\
\text { absorption } \\
\text { (BBB) }\end{array}$ & $\begin{array}{l}\text { Human } \\
\text { intestinal } \\
\text { absorption } \\
\text { (HIA) }\end{array}$ & $\begin{array}{l}\text { AMES } \\
\text { toxicity }\end{array}$ & Carcinogenicity & Status \\
\hline 1. & Cannabidiol & $\mathrm{BBB}+$ & $\mathrm{HIA}+$ & $\begin{array}{l}\text { Non } \\
\text { AMES } \\
\text { toxic }\end{array}$ & $\begin{array}{l}\text { Non- } \\
\text { carcinogens }\end{array}$ & Accepted \\
\hline 2. & Curcumin & $\mathrm{BBB}+$ & $\mathrm{HIA+}$ & $\begin{array}{l}\text { Non } \\
\text { AMES } \\
\text { toxic }\end{array}$ & $\begin{array}{l}\text { Non- } \\
\text { carcinogens }\end{array}$ & Accepted \\
\hline 3. & Resveratrol & BBB+ & $\mathrm{HIA+}$ & $\begin{array}{l}\text { Non } \\
\text { AMES } \\
\text { toxic }\end{array}$ & $\begin{array}{l}\text { Non- } \\
\text { carcinogens }\end{array}$ & Accepted \\
\hline 4. & $\begin{array}{l}\text { Ginsenoside } \\
\text { RG1 }\end{array}$ & BBB+ & $\mathrm{HIA+}$ & $\begin{array}{l}\text { Non } \\
\text { AMES } \\
\text { toxic }\end{array}$ & $\begin{array}{l}\text { Non- } \\
\text { carcinogens }\end{array}$ & Accepted \\
\hline 5. & Sulforaphane & BBB+ & $\mathrm{HIA+}$ & $\begin{array}{l}\text { Non } \\
\text { AMES } \\
\text { toxic }\end{array}$ & Carcinogens & Rejected \\
\hline
\end{tabular}

Table 3: Summary of binding site prediction granularity: Properties and druggability for CD40

\begin{tabular}{|lllll|}
\hline S.No. & Name of pocket & Volume $\left(\AA^{3}\right)$ & Surface $\left(\AA^{2}\right)$ & Drug score \\
\hline 1. & P_0 & 269.18 & 471.12 & 0.62 \\
\hline 2. & P_1 & 251.14 & 588.78 & 0.55 \\
\hline 3. & P_2 & 239.81 & 529.8 & 0.35 \\
\hline 4. & P_3 & 167.3 & 467.97 & 0.48 \\
\hline 5. & P_4 & 137.86 & 385.35 & 0.35 \\
\hline
\end{tabular}

Table 4: Summary of Protein-ligand interaction analysis of CD40 with natural compounds 


\begin{tabular}{|llllllll|}
\hline S.No. & Protein & Compound & RMSD & $\begin{array}{l}\text { Binding } \\
\text { energy } \\
\text { (Kcal/Mol) }\end{array}$ & $\begin{array}{l}\text { Inhibition } \\
\text { constant } \\
\text { (Ki) }\end{array}$ & $\begin{array}{l}\text { No of H } \\
\text { bonds } \\
\text { (drug- } \\
\text { enzyme) }\end{array}$ & $\begin{array}{l}\text { Amino acid } \\
\text { involved in } \\
\text { interaction }\end{array}$ \\
\hline 1. & CD40 & Curcumin & 78.505 & -4.69 & $\begin{array}{l}367.48 \\
\mu M\end{array}$ & 2 & $\begin{array}{l}\text { Asp243, } \\
\text { Ser245 }\end{array}$ \\
\hline 2. & CD40 & Cannabidiol & 290.530 & -4.22 & $\begin{array}{l}805.16 \\
\mu M\end{array}$ & 2 & Ser245 \\
\hline 3. & CD40 & Resveratrol & 75.763 & +59.00 & & 5 & $\begin{array}{l}\text { Val175, } \\
\text { Ala173, } \\
\text { lle171, } \\
\text { Gly227 }\end{array}$ \\
\hline
\end{tabular}

Table 5: Summary of Binding site prediction granularity: Properties and druggability for CSF1R

\begin{tabular}{|lllll|}
\hline S.No. & Name of pocket & Volume $\left(\AA^{3}\right)$ & Surface $\left(\AA^{2}\right)$ & Drug score \\
\hline 1. & P_0 & 1254.85 & 1374.39 & 0.82 \\
\hline 2. & P_1 & 216.58 & 278.22 & 0.54 \\
\hline 3. & P_2 & 133.95 & 240.95 & 0.21 \\
\hline 4. & P_3 & 124.03 & 229.78 & 0.3 \\
\hline 5. & P_4 & 102.34 & 259.98 & 0.18 \\
\hline 6. & P_5 & 213.95 & 366.73 & 0.49 \\
\hline 7. & P_6 & 207.04 & 165.75 & 0.46 \\
\hline 8. & P_7 & 168.32 & 294.79 & 0.39 \\
\hline 9. & P_8 & 164.35 & 365.14 & 0.32 \\
\hline 10. & P_9 & 160.96 & 308.21 & 0.28 \\
\hline 11. & P_10 & 152.13 & 165.39 & 0.48 \\
\hline 12. & P_11 & 151.74 & 247.4 & 0.37 \\
\hline 13. & P_12 & 144.45 & 281.66 & 0.43 \\
\hline
\end{tabular}

Table 6: Summary of Protein-ligand interaction analysis of CSF1R with natural compounds 


\begin{tabular}{|c|c|c|c|c|c|c|c|}
\hline S.No. & Protein & Compound & RMSD & $\begin{array}{l}\text { Binding } \\
\text { energy } \\
\text { (Kcal/Mol) }\end{array}$ & $\begin{array}{l}\text { Inhibition } \\
\text { constant } \\
\text { (Ki) }\end{array}$ & $\begin{array}{l}\text { No of H } \\
\text { bonds } \\
\text { (drug- } \\
\text { enzyme) }\end{array}$ & $\begin{array}{l}\text { Amino acid } \\
\text { involved in } \\
\text { interaction }\end{array}$ \\
\hline \multirow[t]{3}{*}{1.} & CSF1R & Curcumin & 69.61 & -4.95 & $\begin{array}{l}236.48 \\
\mu \mathrm{M}\end{array}$ & 4 & $\begin{array}{l}\text { Arg579, } \\
\text { Gly603, }\end{array}$ \\
\hline & & & & & & & Gly605, \\
\hline & & & & & & & His655 \\
\hline \multirow[t]{2}{*}{2.} & CSF1R & Cannabidiol & 247.17 & -4.75 & 328.22 & 3 & Leu588, \\
\hline & & & & & & & Asp670 \\
\hline \multirow[t]{3}{*}{3.} & CSF1R & Resveratrol & 64.586 & -5.91 & $\begin{array}{l}46.94 \\
\mu M\end{array}$ & 4 & $\begin{array}{l}\text { Lys616, } \\
\text { Cys666, }\end{array}$ \\
\hline & & & & & & & Gly669, \\
\hline & & & & & & & Phe797 \\
\hline
\end{tabular}

\section{Figures}

\section{Figure 1}

DoGSiteScorer analysis showed predicted potential drug binding sites (pockets) on CD40 protein 3D structure. Out of 4 pockets for drug binding detected, Curcumin (a) and Cannabidiol (b) as ligand showed its binding to drug pocket 0 , Ginsenosides (c) and Resveratrol (d) do not show binding on predicted drug binding sites whereas Sulforaphane (e) binds to pocket 2 .

\section{Figure 2}

LigPlot Plus analysis of Autodock result generated 2D ligand-protein interaction diagram depicting hydrogen bonds between amino acid residues of CD40 with Curcumin (a), Cannabidiol (b), Resveratrol (c), and Sulforaphane (d). The hydrogen bond has been shown in the green dotted line with a distance of protein and ligand hydrogen bond mentioned in Angstroms $(\AA)$. 


\section{Figure 3}

DoGSiteScorer analysis showed predicted potential drug binding sites (pockets) on CSF1R protein 3D structure. Out of 13 pockets for drug binding detected, Curcumin (a) does not show binding on predicted drug binding sites, Cannabidiol (b) and Resveratrol (d) as ligand showed its binding to drug pocket 0 whereas Ginsenosides (c) and Sulforaphane (e) binds to pocket 6 and 8, respectively.

A

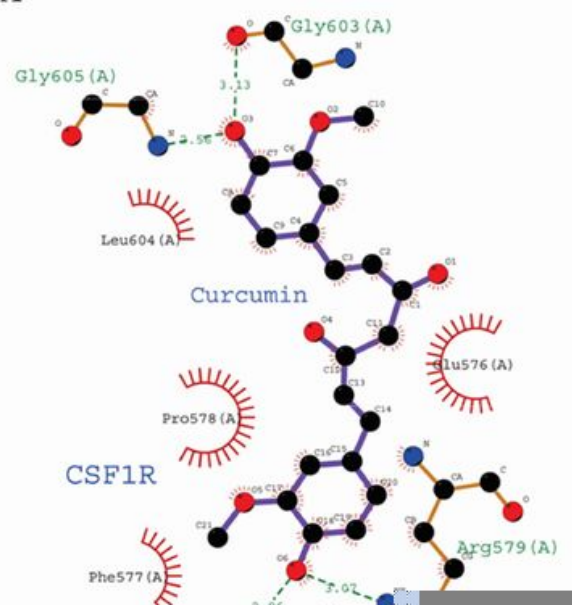

B

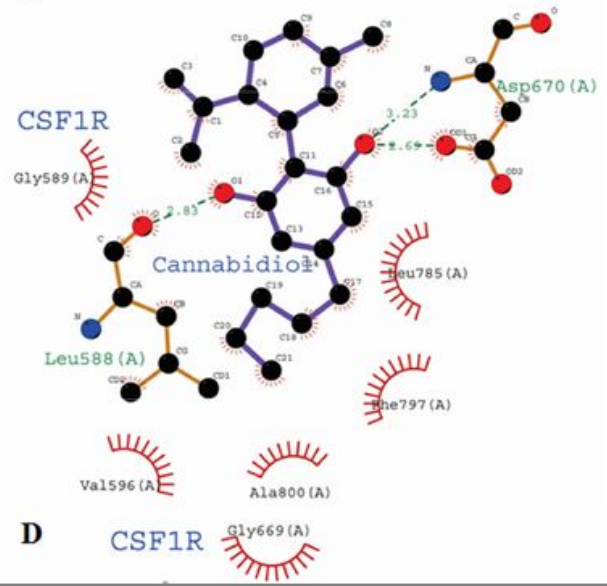

C Ginsenosides $3_{\pi \pi m}^{\text {Leu649 (A) }}$

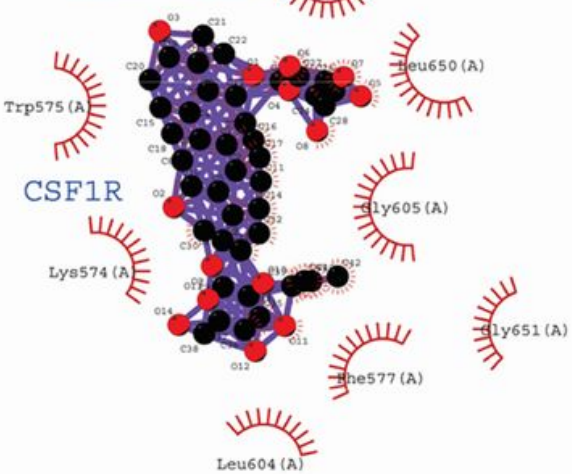

E

㪴eu851 (A)

\section{Figure 4}

LigPlot Plus analysis of Autodock result generated 2D ligand-protein interaction diagram depicting hydrogen bonds between amino acid residues of CSF1R with Curcumin (a), Cannabidiol (b), Ginsenosides (c), Resveratrol (d), and Sulforaphane (e). The hydrogen bond has been shown in green dotted line with a distance of protein and ligand hydrogen bond mentioned in Angstroms 
Diagrammatic representation showing possible interaction of Curcumin, Cannabidiol, and Resveratrol with CD40 and CSR1F on microglia surface which may further influence microglia phenotype, its activation status, and inflammatory response in CNS disease conditions.

\section{Supplementary Files}

This is a list of supplementary files associated with this preprint. Click to download.

- SupplementaryFigure1.pdf

- SupplementaryFigure2.pdf

- SupplementaryFigure3.pdf

- SupplementaryFigure4.pdf

- SupplementaryFigure5.pdf

- SupplementaryFigure6.pdf 